\title{
GEOSPATIAL ANALYSIS OF URBAN LAND USE PATTERN ANALYSIS FOR HEMORRHAGIC FEVER RISK - A REVIEW
}

\author{
Izzah L.N, Majid Z, Ariff M.A.M, Fook C.K \\ Geospatial Imaging \& Information Research Group,Faculty Geionformation and Real Estate, Universiti Teknologi Malaysia, \\ Malaysia \\ zulkeplimajid@utm.my
}

KEY WORDS: Land Use, Land Cover, Hemorrhagic Fever, Vector, Dengue Fever, Malaria, Lassa Fever

\begin{abstract}
:
Human modification of the natural environment continues to create habitats in which vectors of a wide variety of human and animal pathogens (such as Plasmodium, Aedes aegypti, Arenavirus etc.) thrive if unabated with an enormous potential to negatively affect public health. Typical examples of these modifications include impoundments, dams, irrigation systems, landfills and so on that provide enabled environment for the transmission of Hemorrhagic fever such as malaria, dengue, avian flu, Lassa fever etc. Furthermore, contemporary urban dwelling pattern appears to be associated with the prevalence of Hemorrhagic diseases in recent years. These observations are not peculiar to the developing world, as urban expansion also contributes significantly to mosquito and other vectors habitats. This habitats offer breeding ground to some vector virus populations. The key to disease control is developing an understanding of the contribution of human landscape modification to vector-borne pathogen transmission and how a balance may be achieved between human development, public health, and responsible urban land use. A comprehensive review of urban land use Pattern Analysis for Hemorrhagic fever risk has been conducted in this paper. The study found that most of the available literatures dwell more on the impact of urban land use on malaria and dengue fevers; however, studies are yet to be found discussing the implications of urban land use on the risk of Ebola, Lassa and other non-mosquito borne VHFs. A relational model for investigating the influence of urban land use change pattern on the risk of Hemorrhagic fever has been proposed in this study.
\end{abstract}

\section{INTRODUCTION}

Urban environment support high concentration of human, domestic pet, and introduced animals that create favourable conditions for the transmission of infectious parasite, such as the Hemorrhagic viruses. The rate of transmission of the parasite increases with the quest for speedy urbanization. Again, the actual process of rapid urbanization is associated with various ecological, social, and economic changes, in both the urban area, and the adjacent natural environment. Consequently, the continuous degradation of the ecosystem poses a threat to the present and future dwelling sustainability. Babanyara et al. (2010) observed that rapid population growth and urbanization were of great concern to the sustainability of cities; therefore, the more people on the earth, the greater the impact on the environment and the resources. Also, literature affirms that urbanization takes place in both developed and developing countries (Al-shalabi et al., 2013). However, speedy urbanization, especially the urban land expansion, and the associated problem of unemployment, poverty, poor sanitary condition and environment degradation pose a formidable challenge in some developing countries (Basnet, 2011; Hove et al., 2013; owoeye and ogundiran, 2014). Be that as it may, the developing countries lack adequate implementation policies to address dwelling and Hemorrhagic risks as a result of speedy urbanization. Nevertheless, adequate insight into the available dwelling patterns and their impact on the spread of Hemorrhagic diseases could fast-track decision making progress for sustainable urbanization.
Viral Hemorrhagic Fevers (VHFs) are found around the world, specific diseases are usually limited to areas where the animals that carry them live. For example, Lassa is limited to rural areas of West Africa where rats and mice carry the virus. Consequently, several literature (Stefani et al., 2013, Hahn et al., 2014, Li et al., 2016, Alimi et al., 2016, Ibekwe, 2012) have investigated land use/land cover classes and some Hemorrhagic diseases. Bulks of these studies were conducted in America, Asia and Australia with much emphasis on mosquito borne diseases such as dengue and malaria fevers. For instance, Messina et al. (2015) investigated the global distribution of Crimean-Congo Hemorrhagic fever (CCHF) using an exhaustive database of human CCHF occurrence records and a niche modeling framework. A greater proportion of shrub or grass land cover was found to be the most important contributor to their model, which predicts highest levels of risk around the Black Sea, Turkey, and some parts of central Asia. It was affirmed that Sub-Saharan Africa shows more localized areas of risk throughout the Sahel and the Cape region. However, studies on land use/land cover classification and other non-mosquito borne Hemorrhagic diseases such as Lassa fever, Ebola, Marburg etc. are yet to be common in current literature. It is therefore, essential to conduct a comprehensive review of the existing literature on urban dwelling pattern and the risks of Hemorrhagic diseases in order to establish the relationship that may exist between them as well as to benchmark the variations in literature on continental basis. This may be remarkable for predicting the spread of such diseases and providing decision support system for health management institutions. Therefore, this paper presents a review on urban dwelling pattern analysis for Hemorrhagic fever risks. 
In what follows, the background of viral hemorrhagic fevers (VHFs) and urban dwelling pattern analysis is covered in Section 2, Section 3 details the types and source of materials utilized in this review while discussing the method adopted for the review. The results and findings of the paper are discussed in Section 4 while Section 5 wraps up the paper with conclusion.

\section{THE BACKGROUND OF VIRAL HEMORRHAGIC FEVERS (VHFs) AND URBAN LAND USE PATTERN ANALYSIS}

\subsection{Viral Hemorrhagic Fevers (Vhfs)}

Viral hemorrhagic fevers (VHFs) refer to a group of illnesses that are caused by several distinct families of viruses (Chollom et al.,2016). These include the Ebola , dengue fever, avian flu, malaria fever, Lassa fever, yellow fever viruses, Crimean-Congo hemorrhagic fever (CCHF), Rift Valley fever (RVF), Hantavirus diseases etc. In general, the term "viral hemorrhagic fever" is used to describe a severe multisystem syndrome (meaning that multiple organ systems in the body are affected). Characteristically, the overall vascular system is damaged, and the body's ability to regulate itself is impaired. These symptoms are often accompanied by hemorrhage (bleeding); however, the bleeding is itself rarely life-threatening. While some types of hemorrhagic fever viruses can cause relatively mild illnesses, many of these viruses like Ebola or Marburg cause severe, life-threatening disease and death (Ajayi et al., 2013).

\subsubsection{Causes And Transmission of VHF}

According to WHO, Viruses belong to several families; for instance, Ebola and Marburg belong to the Filoviridae family; Hantaviruses, CCHF and RVF belong to the Bunyaviridae family; Lassa belongs to the Arenaviridae family; stomatitis and rabies belong to Rhabdovaridae; while malaria, dengue and yellow fever belong to the Flaviviridae family. Viruses that cause hemorrhagic fevers are transmitted by mosquitoes (dengue, malaria, yellow fever, RVF), ticks (CCHF), rodents (Hantavirus), or bats (Ebola, Marburg). For Ebola and Marburg viruses, humans have been infected from contact with tissues of diseased non-human primates (monkeys and apes) and other mammals, but most human infections have resulted from direct contact with the body fluids or secretions of infected patients. Humans who develop CCHF usually become infected from a tick bite but can also acquire the virus from direct contact with blood or other infected tissues from livestock or from infected patients.

RVF can be acquired either by mosquito bite or by direct contact with blood or tissues of infected animals (mainly sheep), including consumption of unpasteurized milk. Lassa fever virus is carried by rodents and transmitted by excreta, either as aerosols or by direct contact. Some viral haemorrhagic fevers have been amplified in hospitals by nosocomial transmission resulting from unsafe procedures, use of contaminated medical devices (including needles and syringes) and unprotected exposure to contaminated body fluids (Kigozi et al., 2015; Asogun et al., 2012; Olugasa et al., 2015; Hahn et al., 2014; Judson et al., 2015; Fhogartaigh and
Aarons, 2015; Messina et al., 2015; Bhatt et al., 2013; WHO, 2012; Adegboye and Kotze, 2014).

\subsubsection{Nature And Distribution Of VHFs}

The haemorrhagic fevers are severe acute viral infections, usually with sudden onset of fever, malaise, headache and myalgia followed by pharyngitis, vomiting, diarrhoea, skin rash and haemorrhagic manifestations. The outcome is fatal in a high proportion of cases sometimes more than 50\%, (Dzotsi et al., 2012). Diseases in this group occur widely in tropical and subtropical regions. Ebola and malaria, dengue haemorrhagic fevers and Lassa fever occur in parts of subSaharan Africa. Crimean-congo haemorragic fever occurs in the steppe regions of central Asia and in central Europe, as well as in tropical and southern Africa (Lai et al., 2015; Kateera et al., 2015).

The distribution of VHF is determined by climate and other geographic factors that influence the development of the diseases' vectors and their parasites at a given time, which is also influenced by environmental changes over time. Ecosystem changes resulting from natural phenomena or human interventions, on a local or global scale, can alter the ecological balance and context in which vectors and their parasites develop and transmit the disease (Patz et al., 2000). According to Patz and Olson (2006), changes in temperature patterns, due to global climate change and in variation in local land use practices, may influence VHF risk.

\subsection{Urban Land Use Pattern Analysis Using GIS And Remote Sensing}

Changes in the uses of land occurring at various spatial levels and within various time periods are the material expressions, among others, of environmental and human dynamics and of their interactions which are mediated by land. Land use is characterised by the arrangements, activities and inputs people undertake in a certain land cover type to produce change or maintain it (FAO/UNEP, 1999).

For the consequences at local and regional levels, the spatial patterns of land use change are as relevant as the aggregate volume of change. Thus, analysis of urban land use/land cover (LU/LC) change is essential for social economic and regional development and environmental changes (Mirkatouli et al., 2015; Chen et al., 2013; Zhang et al., 2013; Barsimantov and Antezana, 2012).

According to Mirkatouli et al. (2015), development of urban region must be managed in such a manner that meet public needs and benefits current and future residents of cities and its surrounding areas, this requires utilisation of specialised tools and techniques such as remote sensing and GIS. Today, there are various approaches to urban studies such as ground survey, photogrammetry and remote sensing. Remote sensing as a major source of data, is used in the study of areas with urban or manmade characteristics, landscapes and natural environments (Peled and Gilichinsky, 2013; Ye and Fang, 2011; Pelorosso et al., 2009; Bhatta, 2009). However, the integration of remote sensing with GIS is now widely preferred for efficient and more accurate urban growth assessment (Hashim et al., 2011; Baja and Arif 2014; Arsanjani et al., 2015 ; Hove et al., 2013).

The definition given by Colwell (1997) to remote sensing as the art, science and technology of obtaining reliable information about physical objects and the environment, through a process of recording, 
measuring and interpreting imagery and digital representation of energy patterns derived from non-contact sensor systems” makes sense in the usage of its data for urban dwelling pattern assessment. Similarly, GIS as described by Malienea et al. (2011) and Nour (2011) to be a technology that makes possible the collection, compilation, analysis, as well as representation of very large amount of hypothetical/ real word data indicates its relevance for adoption in urban dwelling pattern studies.

In view of these, a number of studies (Nour, 2011; Hui-Hui et al., 2012) have been conducted on urban dwelling pattern analysis using remote sensing and GIS; these are found within a popular caption of land use/land cover pattern analysis. Land cover concerns the physical material observed at the earth surface (such as forests, water bodies and bare rock); Land use is related to the human use of the land and integrates socio-economic and cultural functions (such as agriculture and housing). Despite their differences, Land cover and Land use are often mapped together and often result from remotely sensed image classifications performed by RS experts. Such classification procedures range from totally unsupervised approach to a full visual interpretation of the images and highly depend on the availability of the remotely sensed data, the availability of experts of the application domain, the adequacy of the data for the question addressed and the competence of the technicians, engineers and/or researchers that perform the image processing. As a result, a wide variety of Land use/Land cover typologies and methodologies can be found in the literature.

Furthermore, in a bid to create comfortable dwelling for man, urban environment have been modified in various ways. These human modifications of the natural environment continues to provide habitats in which vectors of a wide variety of human and animal pathogens thrive with an enormous potential to negatively affect public health if left unchecked. This underscores the need for numerous studies on urban land use classification and diseases hazard risks found in current literature (see Table 1). Some authors have directly related environmental alteration to cases of VHF such as malaria and dengue.

\section{MATERIALS AND METHODS}

In conducting this review, five families of hemorrhagic fever namely; the Arenaviridae, the Bunyaviridae, the Filoviridae, the Flaviviridae, and the Rhabdoviridae were identified. Available literature discussing urban dwelling pattern and some of the VHFs in relation to the six continents of the world was utilized. The publications selected for the review include the original research articles using remotely sensed LU/LC information (i.e only focused on the explicit LU/LC types), with studies applied to various types of VHFs (considering vectors and parasites).

Referenced articles using a LU/LC characterization and urban land use pattern analysis for the study of hemorrhagic fever risk across the globe were isolated by performing queries in ISI Web of Knowledge databases: Web of Science, Medline, Journal Citation Reports, Google Scholar, PubMed and Current Contents Connect. The keywords and expressions chosen to construct database queries were: malaria, dengue, fever, Lassa, "urban land cover pattern" OR "urban land use pattern”, "remote sensing", "GIS”, "risk factor”, “Asia”, "South America”, "Africa”, "Europe”, "North America”. The queries were defined by the conjunction of two or more key words and/or expressions. A total of 15 recently published articles from 2011 to 2016 were identified on the subject matter. The identified articles were classified into two broad types: (i) urban land use pattern analysis (6 articles) and (ii) urban land use pattern analysis for VHFs (12 articles). These articles were isolated as the baseline articles for the review. Table $1 \mathrm{a}$ and $1 \mathrm{~b}$ shows the summary of the articles in accordance to their classification. 
The International Archives of the Photogrammetry, Remote Sensing and Spatial Information Sciences, Volume XLII-4/W1, 2016 International Conference on Geomatic and Geospatial Technology (GGT) 2016, 3-5 October 2016, Kuala Lumpur, Malaysia

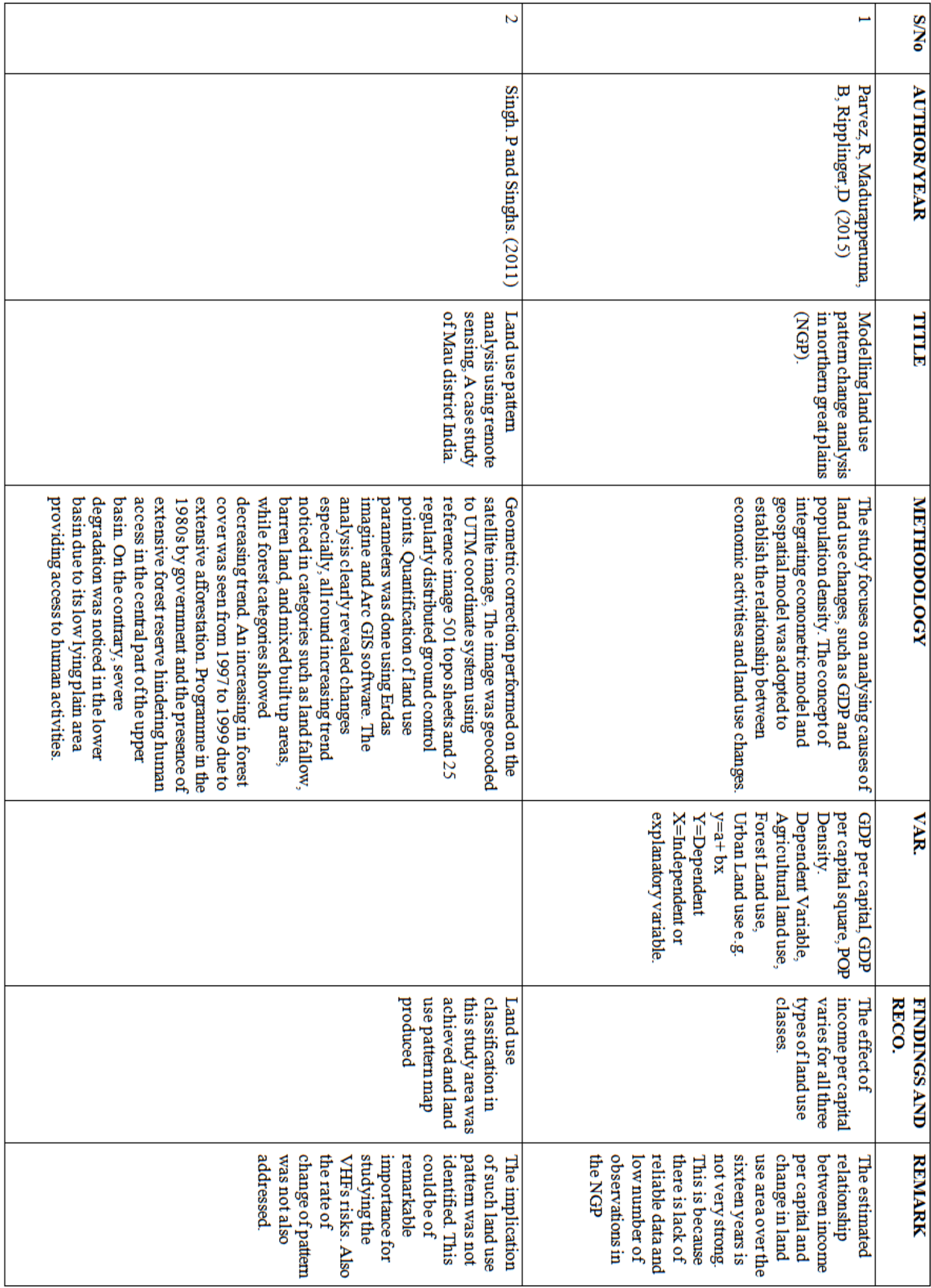




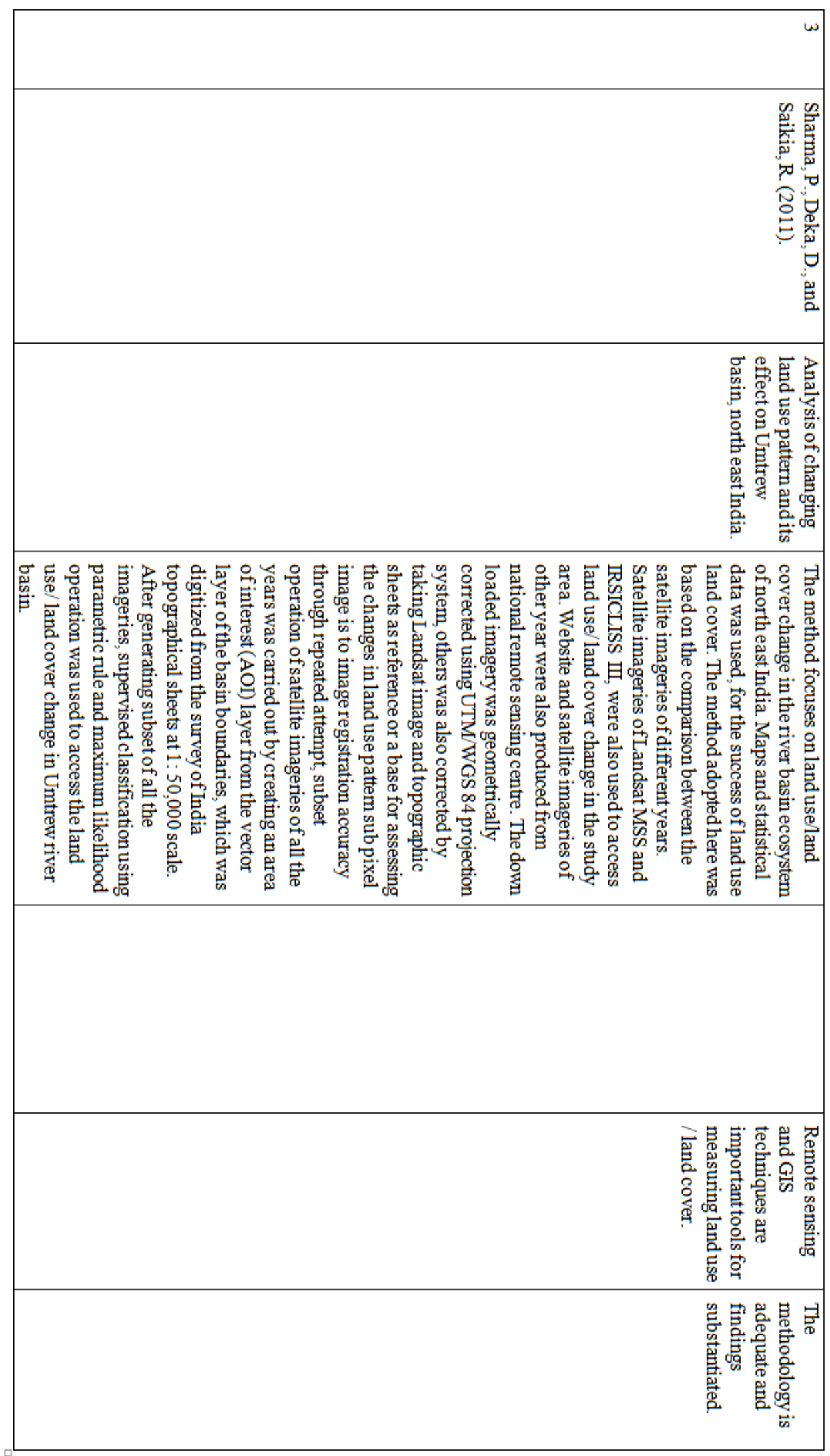


The International Archives of the Photogrammetry, Remote Sensing and Spatial Information Sciences, Volume XLII-4/W1, 2016 International Conference on Geomatic and Geospatial Technology (GGT) 2016, 3-5 October 2016, Kuala Lumpur, Malaysia

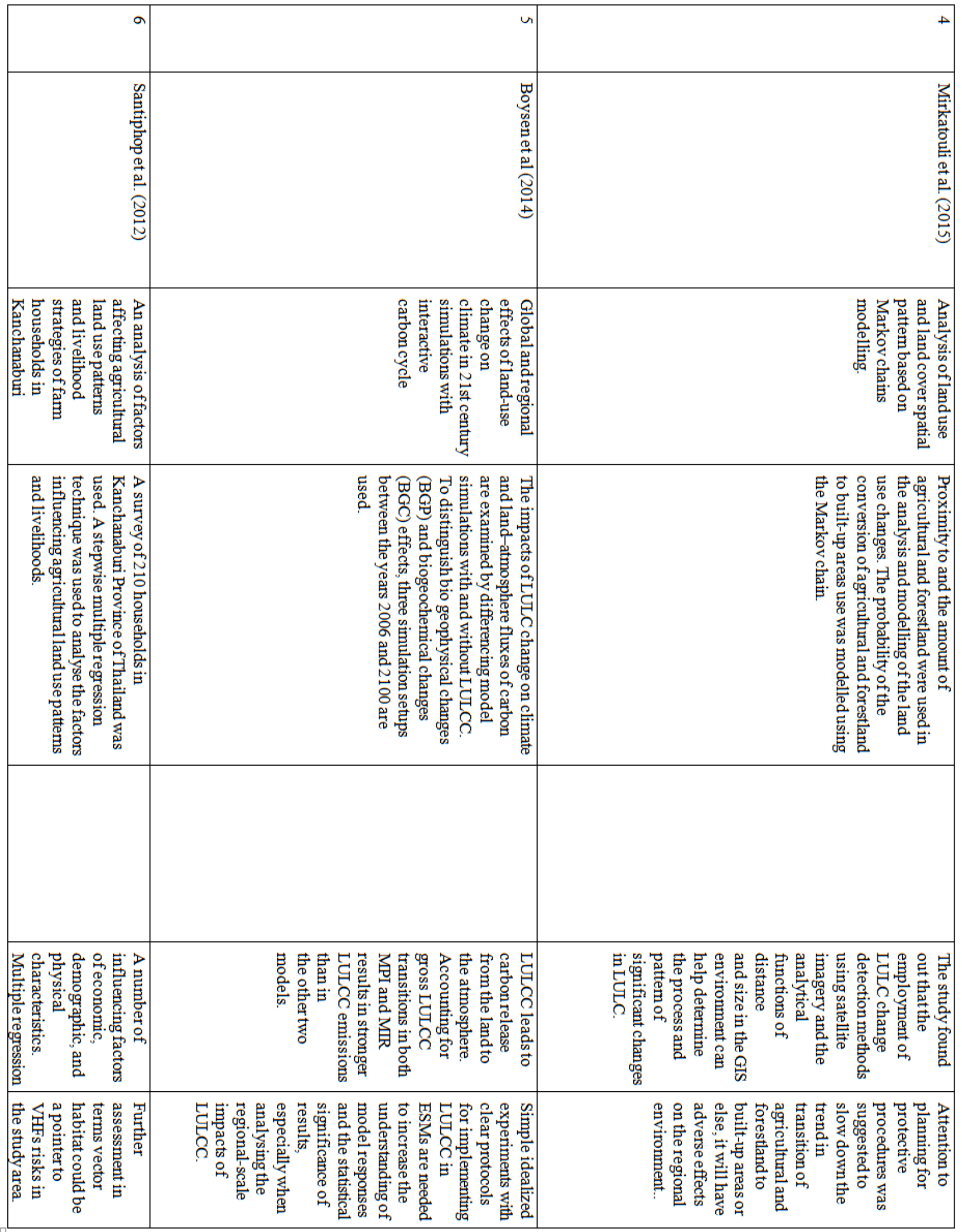




\begin{tabular}{|c|c|c|c|}
\hline$w$ & $N$ & 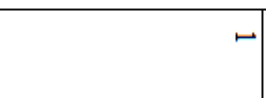 & $\begin{array}{l}n \\
z \\
z\end{array}$ \\
\hline 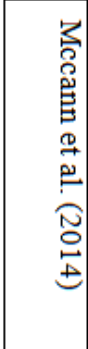 & 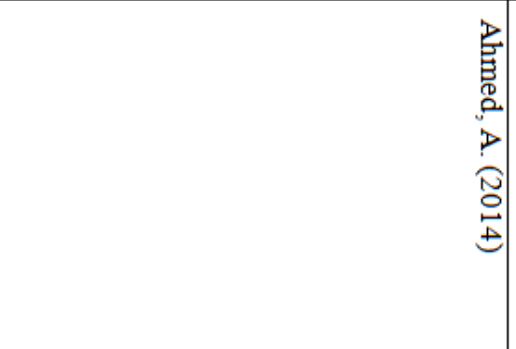 & 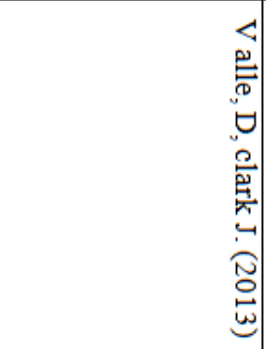 & 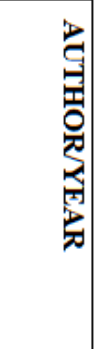 \\
\hline 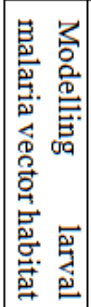 & 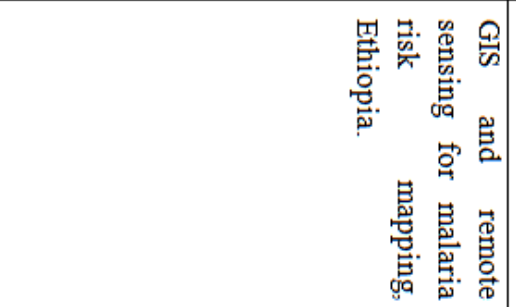 & 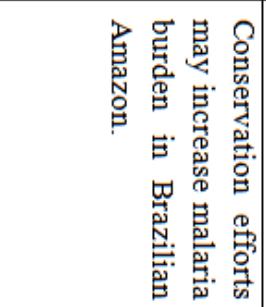 & 目 \\
\hline 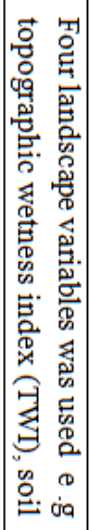 & 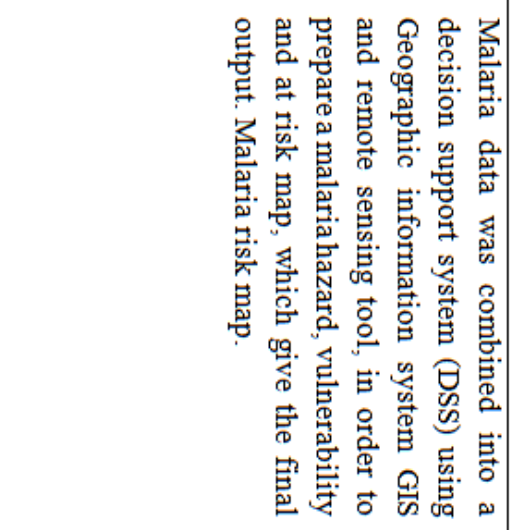 & 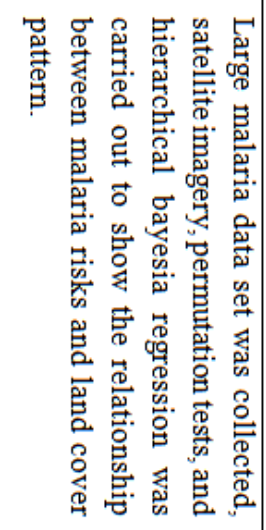 & 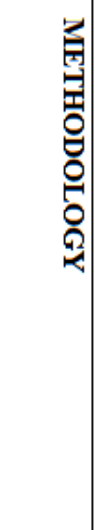 \\
\hline & & & 党 \\
\hline \multirow[t]{2}{*}{ 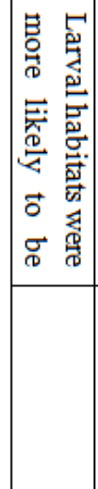 } & 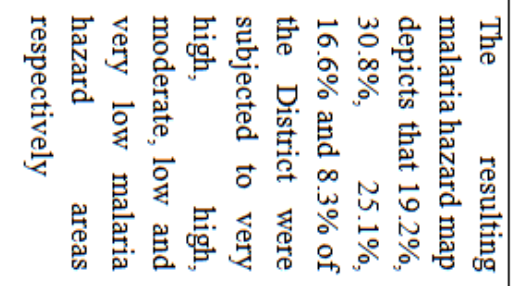 & 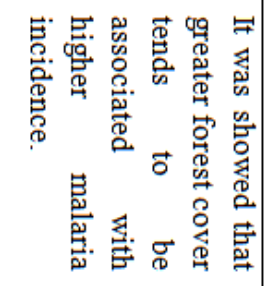 & 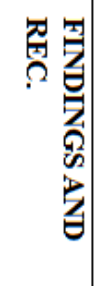 \\
\hline & & 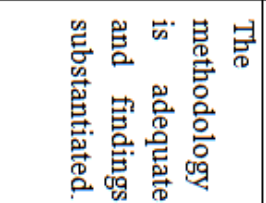 & 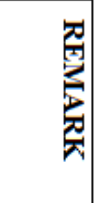 \\
\hline
\end{tabular}

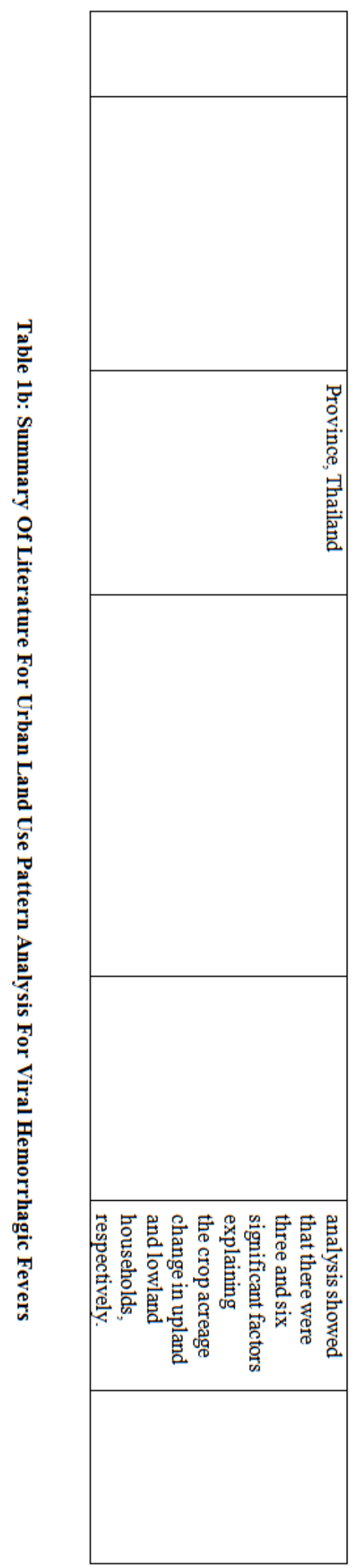


The International Archives of the Photogrammetry, Remote Sensing and Spatial Information Sciences, Volume XLII-4/W1, 2016 International Conference on Geomatic and Geospatial Technology (GGT) 2016, 3-5 October 2016, Kuala Lumpur, Malaysia

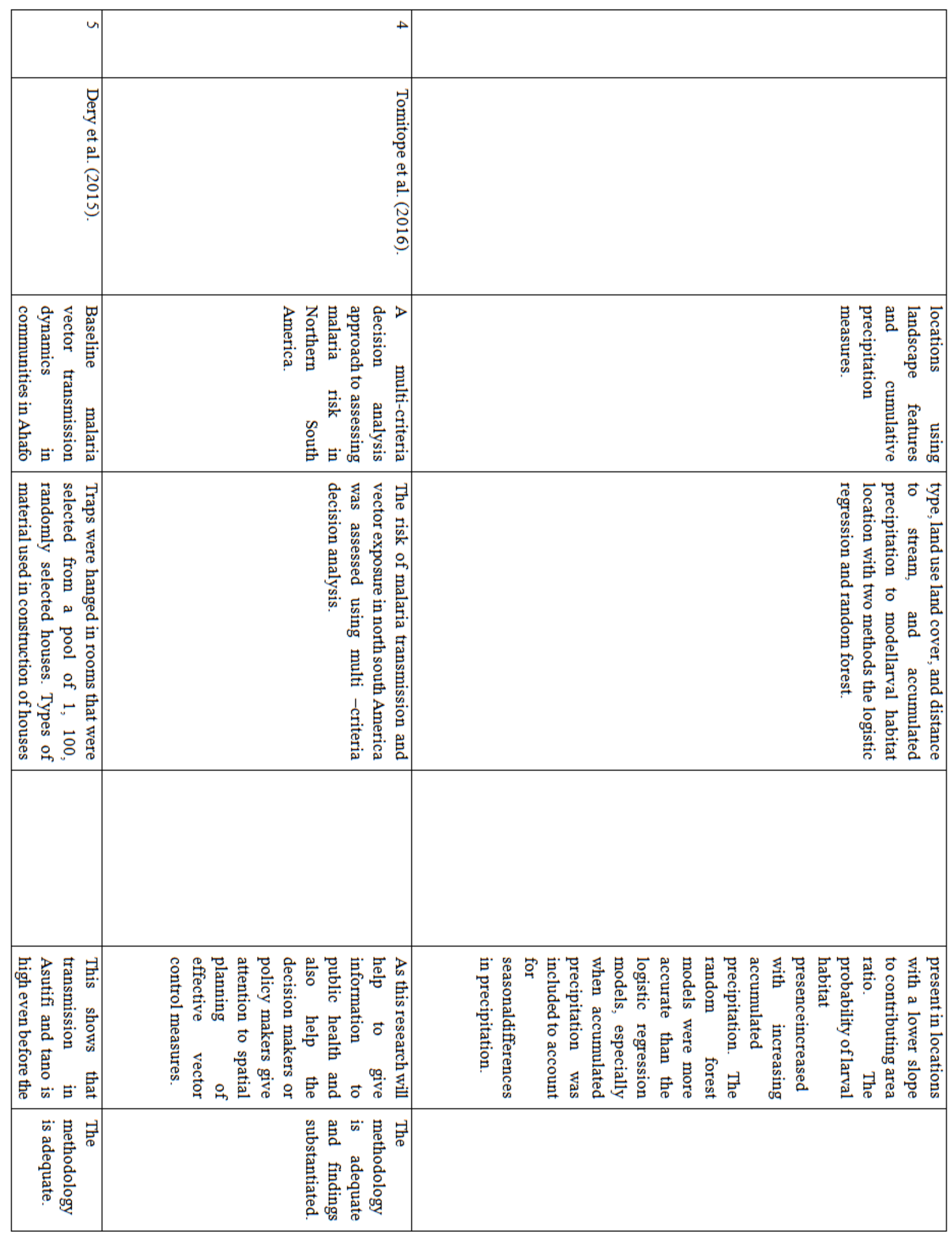


The International Archives of the Photogrammetry, Remote Sensing and Spatial Information Sciences, Volume XLII-4/W1, 2016 International Conference on Geomatic and Geospatial Technology (GGT) 2016, 3-5 October 2016, Kuala Lumpur, Malaysia

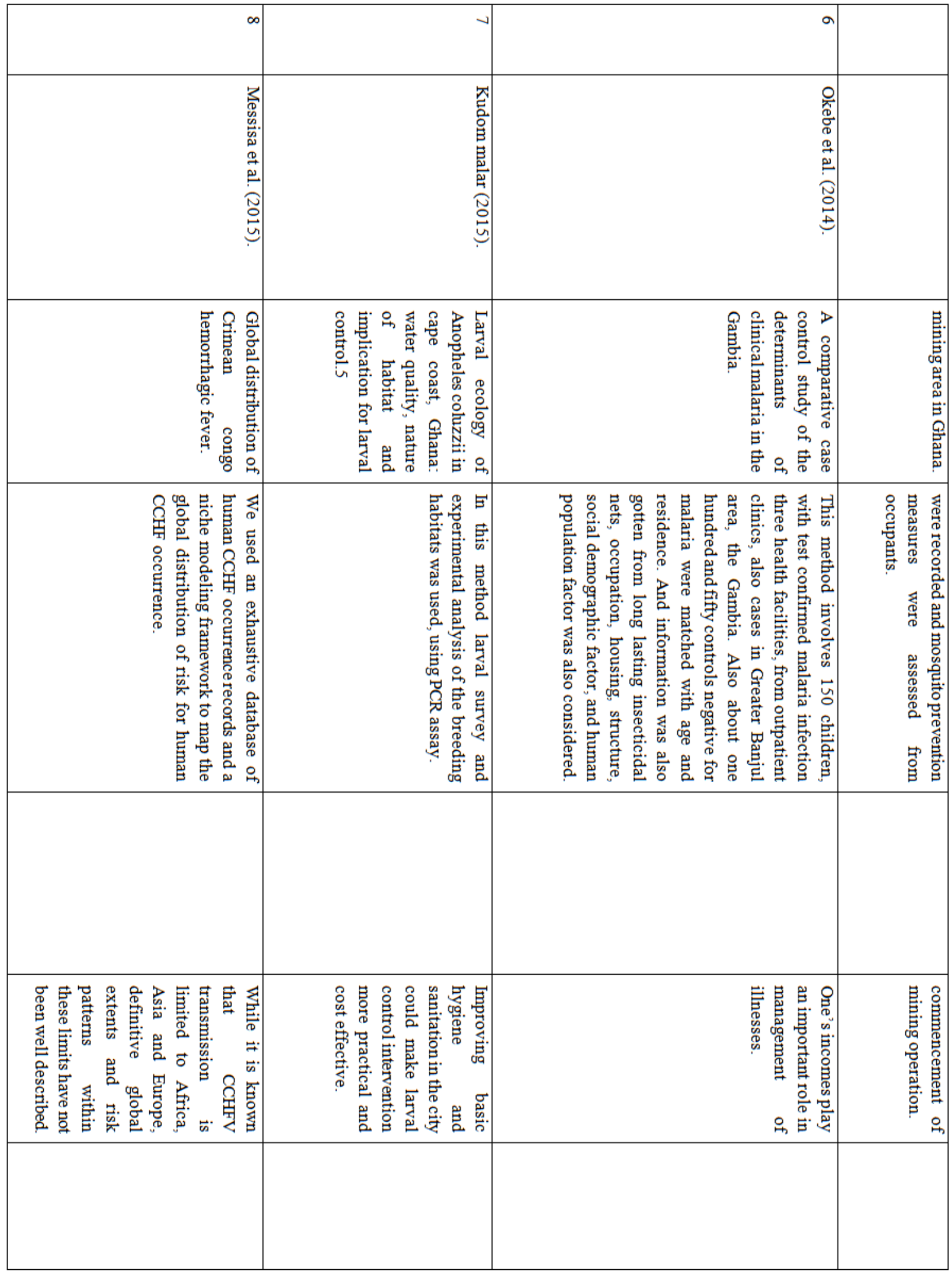


The International Archives of the Photogrammetry, Remote Sensing and Spatial Information Sciences, Volume XLII-4/W1, 2016 International Conference on Geomatic and Geospatial Technology (GGT) 2016, 3-5 October 2016, Kuala Lumpur, Malaysia

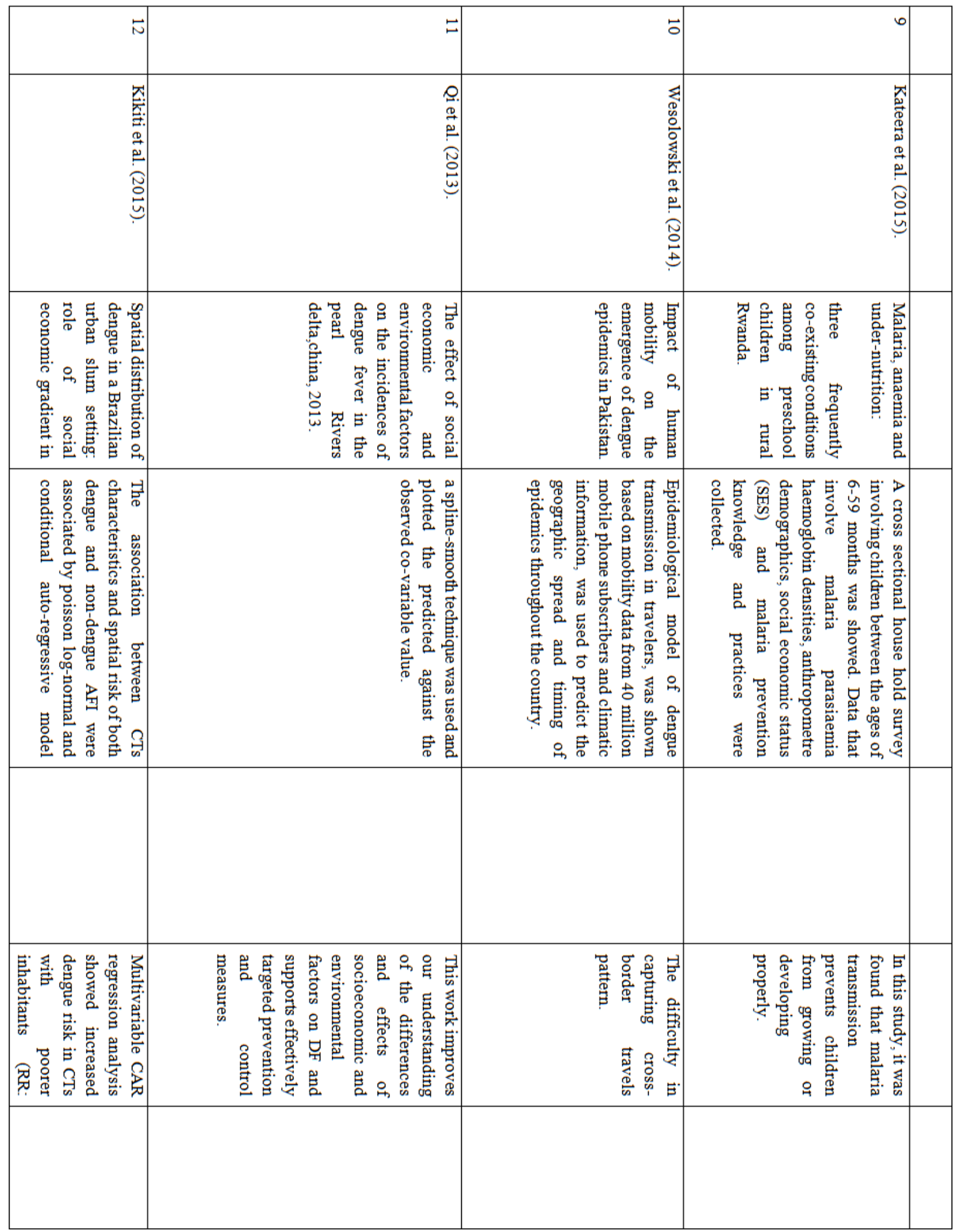


The International Archives of the Photogrammetry, Remote Sensing and Spatial Information Sciences, Volume XLII-4/W1, 2016 International Conference on Geomatic and Geospatial Technology (GGT) 2016, 3-5 October 2016, Kuala Lumpur, Malaysia

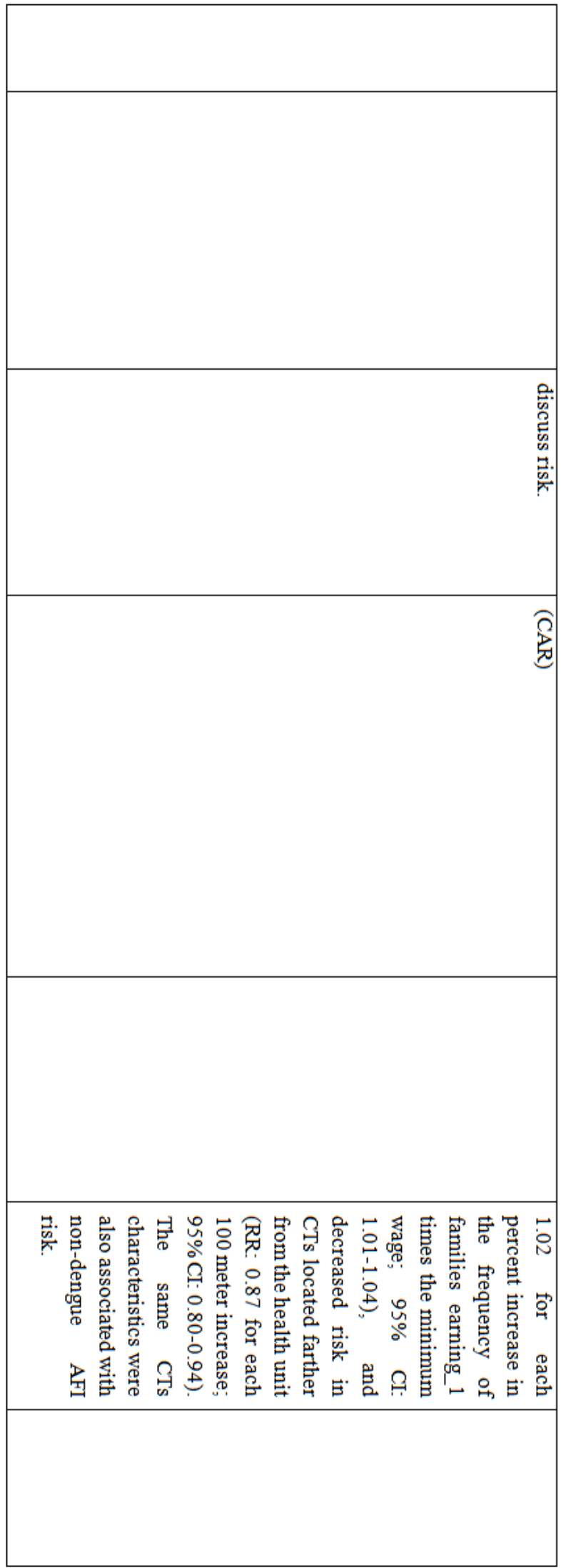




\section{FINDINGS OF THE REVIEW AND DISCUSSION}

The findings from this review are discussed based on the classifications as summarised in the table above. Variable studies exist for different hemorrhagic fevers in different part of the world. This could be attributed to the variations in government response to cases of endemic diseases, cultural differences and the nature of urban life style.

\subsection{Urban Land Use Pattern Analysis And VHFs Risks}

The use of remote sensing (RS) to provide new insights for epidemiological studies was identified very early (Hopley, 1978) as many diseases have been linked to environmental features. A literature review by Herbreteau et al. (2007) found that RS was often, and increasingly, used to study parasitic diseases (59\% of studies) including malaria (16\% of studies).

The challenge of studying VHFs is on identifying all the natural factors (such as seasonality, rainfall, temperature, humidity, surface water and vegetation) and anthropogenic elements (such as agriculture, irrigation, deforestation, urbanization and movements of populations) of the study area, and how to link them with either the incidence of disease or the presence of vectors whilst also integrating temporal and spatial variations. This will help to identify the risk factors from the set of possible environmental parameters. One approach is to link VHFs and land cover (LC) and/or land use (LU) characteristics (Curran et al., 2000). Within such a methodological framework, (Ostfeld et al., 2005) suggest that using more explicit landscape approaches to study ecoepidemiological systems could improve the understanding and prediction of the disease risk.

Landscape composition (the number and types of patches) and configuration (the spatial relationships among patches) must be considered alongside the set of highly localized biotic and abiotic features. Within the framework of the study of landscape ecological functions (also referred to as landscape ecology), there are many ways to characterize the landscape, around point samples or LU/LC patches. This raises questions of objectivity, relevance and adequacy when carrying out environmental characterization. Some studies have therefore tried to standardize and evaluate the effectiveness of the characterization methods (Tischendorf et al., 2003; Palaniyandi and Mariappan, 2012) or to objectify them (Stefani et al., 2011). Studies relating LU/LC with VHFs varies in terms of the VHF families and geographical regions.

\subsubsection{Urban Land Use Pattern Analysis For Malaria}

Several studies discussing urban land use pattern and the risks of malaria fever across the globe have become popular in recent literature. In South America for instance, Olson et al. (2010) studied malaria in Mâncio Lima County, Brazil, in 2006. Adjusting for population, access to care and district size, a $4.3 \%$ increase in deforestation between 1997 and 2000 was associated with a 48\% increase in malaria risk. Vittor et al. (2006) and Vittor et al. (2009) suggested that deforestation and other human environmental alteration favour the presence of both Anopheles darlingi larvae and adults in the Peruvian Amazon. However, Conn et al. (2002) and Moreno et al. (2007) suggested that human intervention could increase the presence of Anopheles marajoara over Anopheles
Darlingi, forest clearance and pollution may be reducing the availability of larval sites for Anopheles darlingi and increase habitats preferred by Anopheles marajoara.

Also, a study on mapping a Knowledge-Based Malaria Hazard Index Related to Landscape Using Remote Sensing has been conducted by $\mathrm{Li}$ et al. (2016) in the Cross-Border area between French Guiana and Brazil. A set of normalized landscape-based hazard indices was developed by computing and combining landscape metrics. Through empirical selection of the best index, the index that successfully represents the current knowledge about the role played by landscape patterns in malaria transmission within the study area was identified. In the northern South America, Alimi et al. (2016) and Piovezan et al. (2012) assessed the risk of malaria transmission and vector exposure using multi-criteria decision analysis, just as Piovezan et al. (2012) performed spatial evaluation of Culicidae (Diptera) larvae from different breeding sites in the São Paulo State municipality of Santa Bárbara d’ Oeste.

Furthermore, a handful of literature on urban land use pattern analysis for malaria risk over Africa also exists. Kelly-Hope and McKenzie (2009) and Olson et al. (2010) conducted a review of entomological inoculation rate measurements and methods across sub-Saharan Africa; this was to examine the distribution of transmission intensity across the sub-region. Extensive georeferenced database and geographical information systems was used to highlight transmission patterns, knowledge gaps, trends and changes in methodologies over time, and key differences between land use, population density, climate, and the main mosquito species. Dery et al. (2015) also conducted a baseline malaria vector transmission dynamics in Ghana for assessing impact of mining Land use in relation to future vector control interventions, the study identified areas where intensified vector control activities would be beneficial. Investigating the contribution of agricultural insecticide use to increasing insecticide resistance in African malaria vectors, Reid and McKenzie, (2016) found that higher resistance in mosquito populations across Africa was associated with agricultural insecticide use. This association appears to be affected by crop type, farm pest management strategy and urban development.

Nevertheless, similar efforts over Europe and Asia have revealed that there are relatively few studies (Al-Eryani et al., 2016; Palaniyandi, 2014; Palaniyandi et al., 2014) on urban land use pattern analysis for malaria risks in those regions. This may be due, in part to strong economic growth in many countries of Europe and Asia, and improved housing standards and control programs (TapiaConyer et al., 2012), which have reduced vector populations in those regions.

\subsubsection{Urban Land Use Pattern Analysis For Dengue}

A number of studies have also discussed urban land use pattern and dengue fever risks recently, significant proportion of these literature emerged from Asia and South America, however, few literature exist that cover other continents of the world.

Large volume of extensive literature on the risks, distribution and mapping of the spread of dengue fever in relation to urban land use pattern has been well reported over Asia than any continent of the world (Wesolowski et al., 2015; Qi et al., 2015; Palaniyandi, 2014b; Palaniyandi, 2014a; Koyadun et al., 2012; Dom et al., 2013; Cheah 
The International Archives of the Photogrammetry, Remote Sensing and Spatial Information Sciences, Volume XLII-4/W1, 2016 International Conference on Geomatic and Geospatial Technology (GGT) 2016, 3-5 October 2016, Kuala Lumpur, Malaysia

et al., 2014; Arima et al., 2013; Wongkoon et al., 2012). Also, Almeida et al. (2009) studied the spatial analysis of dengue and the socioeconomic context in South eastern Brazil, the study found that problems related to basic sanitation contribute decisively to increase in the risk of the disease. Furthermore, the spatial distribution of risks of dengue fever have been recently studied (Kikuti et al., 2015; Barbosa et al., 2014; Allicock et al., 2012), it was found that lower neighbourhood socioeconomic status was independently associated with increased risk of dengue which suggested that, in slum communities with high levels of absolute poverty, factors associated with the social gradient influence dengue transmission. While identifying poor geographic access to health services as a possible barrier to identifying both dengue and non-dengue cases, further spatial studies that could account for such potential source of bias have been recommended in these studies. Therefore, utilising urban land use metrics in addition to socioeconomics may be a pointer to the desired goal.

\subsubsection{Urban Land Use Pattern Analysis For Non-Mosquito Borne VHFs}

The non-mosquito borne VHFs include basically, the Arenaviridae (e.g. Lassa fever), Filoviridae (e.g. Ebola and Marburg) and some members of Rhabdovaridae (e.g. rabies) families. Unlike the mosquito-borne VHFs, less attention has been given to the study of non-mosquitoes borne VHFs risk and urban land use pattern analysis. This is evident by the virtually none existence of any specific article in the current literature discussing the land used pattern analysis for families of the non-mosquito borne Hemorrhagic fever risks. However, these families of VHFs present peculiar features as they can cause severe, life-threatening ailments (Ibekwe, 2012; Chowell and Nishiura, 2014; Ibekwe et al., 2011). Typical among them are Ebola and Lassa fevers whose recent outbreaks has posed serious health challenges in the world especially in sub-Sahara Africa. For instance, it has been reported in medical literature that rats are the key vectors of lassa virus (Yun and Walker, 2012). The short incubation period of these diseases, their high infectious characteristics and high mortality rate associated with the spread has led to their classification as high risk health issue (Ibekwe et al., 2011). The challenge therefore, is to determine the link between these diseases and urban land use pattern

4.2 A Relational Framework for the Prediction of NonMosquito Borne VHFs Risks Using Urban Land Use Pattern Analysis

It is obvious that most of the vectors of the non-mosquito borne VHFs (e.g. rats, monkeys, bats etc.) cohabits with man in urban environments, such ecology may be influenced by certain human activities or natural events relating to urban land use. Therefore, the critical questions to be addressed in subsequent studies include:

(i) Is there any relationship between urban land use pattern and non-mosquito borne Hemorrhagic fevers?

(ii) How may this relationship (if it exists) provides leading information for the prediction of VHFs risks?

In order to address these issues and establish the desired relationship, there is the need to first, construct a relational framework. This will help in understanding the relationship between land use characteristics and the incidences of hemorrhagic fevers; Figure 1 depicts the relational framework.

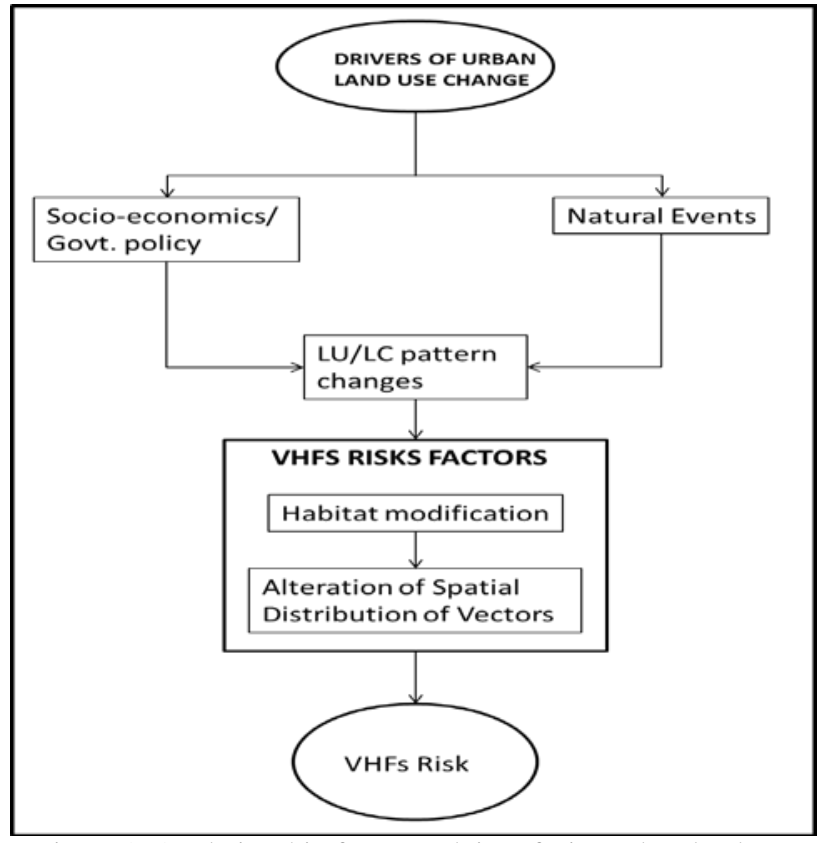

Figure 1: A relationship framework interfacing urban land use pattern changes with the VHFs riskS.

This relational framework as shown in Figure 1 indicates a possible relationship between hemorrhagic fevers and land use change pattern. Since the vectors for non-mosquito VHFs also thrive well in a favourable habitat, modification of such habitats occasioned by land use/land cover change pattern would equally influences the spatial distribution of the vectors. Hence analysis of the urban land use pattern could certainly give indication of the non-mosquito borne VHFs such as Lassa or Ebola fevers. This addresses the questions raised above. Thus, a GIS model can be utilised to analyse the land use change pattern metrics, such a system requires the remotely sensed data (satellite imageries) as input.

\section{CONCLUSIONS}

This paper has reviewed varieties of studies on urban land use pattern analysis for Hemorrhagic fevers as found in recent literature. Spatial variation of available literature on continental basis was investigated; findings from all the studies suggest that urban land use pattern analysis is crucial for the prediction of VHFs risks. Bulk of the literature dwell on land use pattern analysis for mosquito borne VHFs such as malaria and dengue fevers risks with little or no similar efforts found on non-mosquito borne Hemorrhagic fevers such as Lassa and Ebola fevers risks. Similarly, majority of the available literature on malaria emerged from the Caribbean (particularly, Brazil) followed by sub-Saharan Africa, while Asia has the most studies on dengue Hemorrhagic fevers. A relational framework for investigating the link between urban land use pattern and the non-mosquito borne VHFs has been designed in this paper, this will serve as a guide for the construction of a GIS based model for prediction of the non-mosquito borne VHFs risk factors. This framework can be said to have provided a preliminary answer to the questions raised in Section 4.2. 


\section{ACKNOWLEDGEMENT}

The authors acknowledge the support and contribution received from the Ministry of Higher Education (MOHE) and Faculty of Geoinformation and Real Estate, Universiti Teknologi Malaysia (UTM). The authors would also like to thank Innovative Engineering Alliance, Universiti Teknologi Malaysia, for providing the fund from vote number 4L149 to enable this study to be carried out.

\section{REFERENCES}

Adegboye, O. \& Kotze, D. (2014). Epidemiological Analysis Of Spatially Misaligned Data: A Case Of Highly Pathogenic Avian Influenza Virus Outbreak In Nigeria. Epidemiology And Infection, 142, 940-949.

Ajayi, N. A., Nwigwe, C. G., Azuogu, B. N., Onyire, B. N., Nwonwu, E. U., Ogbonnaya, L. U., Onwe, F. I., Ekaete, T., Günther, S. \& Ukwaja, K. N.(2013). Containing A Lassa Fever Epidemic In A Resource-Limited Setting: Outbreak Description And Lessons Learned From Abakaliki, Nigeria (January-March 2012). International Journal Of Infectious Diseases, 17, E1011-E1016.

Al-Eryani, S. M. A., Kelly-Hope, L., Harbach, R. E., Briscoe, A. G., Barnish, G., Azazy, A. \& Mccall, P. J. (2016). Entomological Aspects And The Role Of Human Behaviour In Malaria Transmission In A Highland Region Of The Republic Of Yemen. Malaria Journal, 15.

Al-Shalabi, M., Billa, L., Pradhan, B., Mansor, S. \& Al-Sharif, A. A. (2013). Modelling Urban Growth Evolution And Land-Use Changes Using GIS Based Cellular Automata And SLEUTH Models: The Case Of Sana'a Metropolitan City, Yemen. Environmental Earth Sciences, 70, 425-437.

Alimi, T. O., Fuller, D. O., Herrera, S. V., Arevalo-Herrera, M., Quinones, M. L., Stoler, J. B. \& Beier, J. C. (2016). A Multi-Criteria Decision Analysis Approach To Assessing Malaria Risk In Northern South America. BMC Public Health, 16, 1.

Allicock, O. M., Lemey, P., Tatem, A. J., Pybus, O. G., Bennett, S. N., Mueller, B. A., Suchard, M. A., Foster, J. E., Rambaut, A. \& Carrington, C. V. (2012). Phylogeography And Population Dynamics Of Dengue Viruses In The Americas. Molecular Biology And Evolution, 29, 1533-1543.

Almeida, A. S. D., Medronho, R. D. A. \& Valencia, L. I. O. (2009). Spatial Analysis Of Dengue And The Socioeconomic Context Of The City Of Rio De Janeiro (Southeastern Brazil). Revista De Saúde Pública, 43, 666-673.

Arima, Y., Edelstein, Z. R., Han, H. K. \& Matsui, S. (2013). Epidemiologic Update On The Dengue Situation In The Western Pacific Region, 2011. Western Pacific Surveillance And Response, 4.

Arsanjani, T. J., Javidan, R., Nazemosadat, M. J., Arsanjani, J. J. \& Vaz, E. (2015). Spatiotemporal Monitoring Of Bakhtegan Lake's Areal Fluctuations And An Exploration Of Its Future Status By Applying A Cellular Automata Model. Computers \& Geosciences,
78, 37-43.

Asogun, D. A., Adomeh, D. I., Ehimuan, J., Odia, I., Hass, M., Gabriel, M., Ölschläger, S., Becker-Ziaja, B., Folarin, O. \& Phelan, E.(2012). Molecular Diagnostics For Lassa Fever At Irrua Specialist Teaching Hospital, Nigeria: Lessons Learnt From Two Years Of Laboratory Operation. Plos Negl Trop Dis, 6, E1839.

Babanyara, Y., Usman, H. \& Saleh, U. (2010). An Overview Of Urban Poverty And Environmental Problems In Nigeria. Journal Of Human Ecology, 31, 135-143.

Baja, S. \& Arif, S. (2014) GIS-Based Modelling Of Land Use Dynamics Using Cellular Automata And Markov Chain. Journal Of Environment And Earth Science. 4, (4), 61-66.

Barbosa, G. L., Donalísio, M. R., Stephan, C., Lourenço, R. W., Andrade, V. R., De Brito Arduino, M. \& De Lima, V. L. C. (2014). Spatial Distribution of The Risk Of Dengue And The Entomological Indicators In Sumaré, State Of São Paulo, Brazil. Plos Negl Trop Dis, 8, E2873.

Barsimantov, J. \& Antezana, J. N. (2012). Forest Cover Change And Land Tenure Change In Mexico's Avocado Region: Is Community Forestry Related To Reduced Deforestation For High Value Crops? Applied Geography, 32, 844-853.

Basnet, P.(2011). An Analysis Of Urbanization Trend, Pattern And Policies In Nepal. Sonsik Journal, 3, 64-71.

Bhatt, S., Gething, P. W., Brady, O. J., Messina, J. P., Farlow, A. W., Moyes, C. L., Drake, J. M., Brownstein, J. S., Hoen, A. G. \& Sankoh, O.( 2013). The Global Distribution And Burden Of Dengue. Nature, 496, 504-507.

Bhatta, B. (2009). Analysis Of Urban Growth Pattern Using Remote Sensing And GIS: A Case Study Of Kolkata, India. International Journal Of Remote Sensing, 30, 4733-4746.

Cheah, W., Ng, K., Marzilawati, A. \& Lum, L. (2014). A Review Of Dengue Research In Malaysia. The Medical Journal Of Malaysia, 69, 59-67.

Chen, X., Bai, J., Li, X. Y., Luo, G. P., Li, J. L. \& Li, B. L.( 2013). Changes In Land Use/Land Cover And Ecosystem Services In Central Asia During 1990-2009. Current Opinion In Environmental Sustainability, 5, 116-127.

Chollom, S. C., Osawe, S., Lar, P., Egah, D. Z., Mamman, I. \& Abimiku, A. L. Analysis Of Reported Cases Of Lassa Fever In Plateau State And The Need For Strategic Action Plan.

Chowell, G. \& Nishiura, H. (2014.) Transmission Dynamics And Control Of Ebola Virus Disease (EVD): A Review. BMC Medicine, $12,1$.

Colwell, R. N. (1997). History And Place Of Photographic Interpretation. Manual Of Photographic Interpretation, 2, 33-48.

Conn, J. E., Wilkerson, R. C., Segura, M. N. O., De Souza, R. T., Schlichting, C. D., Wirtz, R. A. \& Póvoa, M. M. (2002). Emergence 
Of A New Neotropical Malaria Vector Facilitated By Human Migration And Changes In Land Use. The American Journal Of Tropical Medicine And Hygiene, 66, 18-22.

Curran, P. J., Atkinson, P. M., Foody, G. M. \& Milton, E. J. (2000). Linking Remote Sensing, Land Cover And Disease. Advances In Parasitology, 47, 37-80.

Dery, D. B., Asante, K. P., Zandoh, C., Febir, L. G., Brown, C., Adjei, G., Antwi-Dadzie, Y., Mahama, E., Tchum, K. \& Dosoo, D. (2015). Baseline Malaria Vector Transmission Dynamics In Communities In Ahafo Mining Area In Ghana. Malaria Journal, 14, 1.

Dom, N. C., Ahmad, A. H., Latif, Z. A., Ismail, R. \& Pradhan, B. (2013). Coupling Of Remote Sensing Data And EnvironmentalRelated Parameters For Dengue Transmission Risk Assessment In Subang Jaya, Malaysia. Geocarto International, 28, 258-272.

Dzotsi, E., Ohene, S., Asiedu-Bekoe, F., Amankwa, J., Sarkodie, B., Adjabeng, M., Thouphique, A., Ofei, A., Oduro, J. \& Atitogo, D. (2012). The First Cases Of Lassa Fever In Ghana. Ghana Med J, 46, 166-70.

Fhogartaigh, C. N. \& Aarons, E. (2015). Viral Haemorrhagic Fever. Clinical Medicine, 15, 61-66.

Hahn, M. B., Gangnon, R. E., Barcellos, C., Asner, G. P. \& Patz, J. A. (2014). Influence Of Deforestation, Logging, And Fire On Malaria In The Brazilian Amazon. Plos One, 9, E85725.

Hashim, M., Mohd Noor, N. \& Marghany, M. (2011). Modeling Sprawl Of Unauthorized Development Using Geospatial Technology: Case Study In Kuantan District, Malaysia. International Journal Of Digital Earth, 4, 223-238.

Herbreteau, V., Salem, G., Souris, M., Hugot, J.-P. \& Gonzalez, J.P. (2007). Thirty Years Of Use And Improvement Of Remote Sensing, Applied To Epidemiology: From Early Promises To Lasting Frustration. Health \& Place, 13, 400-403.

Hopley, D. (1978). Aerial Photography And Other Remote Sensing Techniques. Coral Reefs: Research Methods, 231-50.

Hove, M., Ngwerume, E. \& Muchemwa, C. (2013). The Urban Crisis In Sub-Saharan Africa: A Threat To Human Security And Sustainable Development. Stability: International Journal Of Security And Development, 2.

Hui-Hui, F., Hui-Ping, L. \& Ying, L. (2012). Scenario Prediction And Analysis Of Urban Growth Using SLEUTH Model. Pedosphere, 22, 206-216.

Ibekwe, T. (2012). Lassa Fever: The Challenges Of Curtailing A Deadly Disease. Pan African Medical Journal, 11.

Ibekwe, T., Okokhere, P., Asogun, D., Blackie, F., Nwegbu, M., Wahab, K., Omilabu, S. \& Akpede, G. (2011). Early-Onset Sensorineural Hearing Loss In Lassa Fever. European Archives Of Oto-Rhino-Laryngology, 268, 197-201.

Judson, S., Prescott, J. \& Munster, V. (2015). Understanding Ebola
Virus Transmission. Viruses, 7, 511-521.

Kateera, F., Mens, P. F., Hakizimana, E., Ingabire, C. M., Muragijemariya, L., Karinda, P., Grobusch, M. P., Mutesa, L. \& Van Vugt, M. (2015). Malaria Parasite Carriage And Risk Determinants In A Rural Population: A Malariometric Survey In Rwanda. Malar J, 14, 16.

Kelly-Hope, L. A. \& Mckenzie, F. E. (2009). The Multiplicity Of Malaria Transmission: A Review Of Entomological Inoculation Rate Measurements And Methods Across Sub-Saharan Africa. Malaria Journal, 8, 1.

Kigozi, S. P., Pindolia, D. K., Smith, D. L., Arinaitwe, E., Katureebe, A., Kilama, M., Nankabirwa, J., Lindsay, S. W., Staedke, S. G. \& Dorsey, G. (2015). Associations Between Urbanicity And Malaria At Local Scales In Uganda. Malaria Journal, 14, 1-12.

Kikuti, M., Cunha, G. M., Paploski, I. A., Kasper, A. M., Silva, M. M., Tavares, A. S., Cruz, J. S., Queiroz, T. L., Rodrigues, M. S. \& Santana, P. M. (2015). Spatial Distribution Of Dengue In A Brazilian Urban Slum Setting: Role Of Socioeconomic Gradient In Disease Risk. Plos Negl Trop Dis, 9, E0003937.

Koyadun, S., Butraporn, P. \& Kittayapong, P. (2012). Ecologic And Sociodemographic Risk Determinants For Dengue Transmission In Urban Areas In Thailand. Interdisciplinary Perspectives On Infectious Diseases, 2012.

Lai, S., Huang, Z., Zhou, H., Anders, K. L., Perkins, T. A., Yin, W., Li, Y., Mu, D., Chen, Q. \& Zhang, Z. (2015). The Changing Epidemiology Of Dengue In China, 1990-2014: A Descriptive Analysis Of 25 Years Of Nationwide Surveillance Data. BMC Medicine, 13, 1.

Li, Z., Roux, E., Dessay, N., Girod, R., Stefani, A., Nacher, M., Moiret, A. \& Seyler, F. (2016). Mapping A Knowledge-Based Malaria Hazard Index Related To Landscape Using Remote Sensing: Application To The Cross-Border Area Between French Guiana And Brazil. Remote Sensing, 8, 319.

Malienea, V., Grigonisb, V., Paleviciusb, V. \& Griffithsc, S. (2011). Geographic Information System: Old Principles With New Capabilities. Urban Design International, AUTHOR COPY 16, 1-6. Doi:10.1057/Udi.2010.25.

Messina, J. P., Pigott, D. M., Golding, N., Duda, K. A., Brownstein, J. S., Weiss, D. J., Gibson, H., Robinson, T. P., Gilbert, M. \& Wint, G. W. (2015). The Global Distribution Of Crimean-Congo Hemorrhagic Fever. Transactions Of The Royal Society Of Tropical Medicine And Hygiene, 109, 503-513.

Mirkatouli, J., Hosseini, A. \& Neshat, A. (2015). Analysis Of Land Use And Land Cover Spatial Pattern Based On Markov Chains Modelling. City, Territory And Architecture, 2, 1-9.

Moreno, J., Rubio-Palis, Y., Páez, E., Pérez, E. \& Sánchez, V . (2007). Abundance, Biting Behaviour And Parous Rate Of Anopheline Mosquito Species In Relation To Malaria Incidence In Gold

HArieżngla.Armedi@af \$malthern

Veterinary Entomology, 21, 339-349. 
Nour, A. M.(2011). The Potential Of GIS Tools In Strategic Urban Planning Process; As An Approach For Sustainable Development In Egypt. Journal Of Sustainable Development, 4, 284.

Olson, S. H., Gangnon, R., Silveira, G. A. \& Patz, J. A. (2010). Deforestation And Malaria In Mancio Lima County, Brazil. Emerg Infect Dis, 16, 1108-1115.

Olugasa, B. O., Odigie, E. A., Lawani, M. \& Ojo, J. F. (2015). Development Of A Time-Trend Model For Analyzing And Predicting Case-Pattern Of Lassa Fever Epidemics In Liberia, 20132017. Annals Of African Medicine, 14, 89.

Organization, W. H. (2012). Global Strategy For Dengue Prevention And Control 2012-2020, World Health Organization.

Ostfeld, R. S., Glass, G. E. \& Keesing, F. (2005). Spatial Epidemiology: An Emerging (Or Re-Emerging) Discipline. Trends In Ecology \& Evolution, 20, 328-336.

Owoeye, J. \& Ogundiran, A. (2014). A Study On Housing And Environmental Quality Of Moniya Community In Ibadan, Nigeria. International Journal Of Physical And Human Geography. 3, (1), .31-45.

Palaniyandi, M. (2014a.) The Environmental Aspects Of Dengue And Chikungunya Outbreaks In India: GIS For Epidemic Control. International Journal Of Mosquito Research, 1, 38-44.

Palaniyandi, M. (2014b). Gis Based Site Selection For Fixing Uv Light Adult Mosquito Trap And Gravid Adult Mosquito Trap For Epidemic Control In The Urban Settlements. International Journal Of Technology Enhancements And Emerging Engineering Research, 3, 156-160.

Palaniyandi, M., Anand, P. \& Maniyosai, R. (2014). Spatial Cognition: A Geospatial Analysis Of Vector Borne Disease Transmission And The Environment, Using Remote Sensing And GIS. Information Systems, 1, 52.

Palaniyandi, M. \& Mariappan, T. (2012). Containing The Spread Of Malaria With Geospatial Tech. Geospatial World Weekly, 8, 1-9.

Patz, J. A., Graczyk, T. K., Geller, N. \& Vittor, A. Y. (2000). Effects Of Environmental Change On Emerging Parasitic Diseases. International Journal For Parasitology, 30, 1395-1405.

Patz, J. A. \& Olson, S. H. (2006). Malaria Risk And Temperature: Influences From Global Climate Change And Local Land Use Practices. Proceedings Of The National Academy Of Sciences, 103, 5635-5636.

Peled, A. \& Gilichinsky, M. (2013). GIS-Driven Classification Of Land Use Using IKONOS Data And A Core National Spatial Information Database. Applied Geomatics, 5, 109-117.

Pelorosso, R., Leone, A. \& Boccia, L. (2009). Land Cover And Land Use Change In The Italian Central Apennines: A Comparison Of Assessment Methods. Applied Geography, 29, 35-48.
Piovezan, R., Azevedo, T. S. D. \& Von Zuben, C. J.( 2012). Spatial Evaluation Of Larvae Of Culicidae (Diptera) From Different Breeding Sites: Application Of A Geospatial Method And Implications For Vector Control. Revista Brasileira De Entomologia, 56, 368-376.

Qi, X., Wang, Y., Li, Y., Meng, Y., Chen, Q., Ma, J. \& Gao, G. F. (2015). The Effects Of Socioeconomic And Environmental Factors On The Incidence Of Dengue Fever In The Pearl River Delta, China, 2013. Plos Negl Trop Dis, 9, E0004159.

Reid, M. C. \& Mckenzie, F. E. (2016). The Contribution Of Agricultural Insecticide Use To Increasing Insecticide Resistance In African Malaria Vectors. Malaria Journal, 15, 1.

Stefani, A., Dusfour, I., Corrêa, A. P., Cruz, M. C., Dessay, N., Galardo, A. K., Galardo, C. D., Girod, R., Gomes, M. S. \& Gurgel, H. (2013). Land Cover, Land Use And Malaria In The Amazon: A Systematic Literature Review Of Studies Using Remotely Sensed Data. Malar J, 12, 10.1186.

Stefani, A., Roux, E., Fotsing, J.-M. \& Carme, B. (2011). Studying Relationships Between Environment And Malaria Incidence In Camopi (French Guiana) Through The Objective Selection Of Buffer-Based Landscape Characterisations. International Journal Of Health Geographics, 10, 1.

Tapia-Conyer, R., Betancourt-Cravioto, M. \& Mendez-Galvan, J. (2012). Dengue: An Escalating Public Health Problem In Latin America. Paediatrics And International Child Health, 32, 14-17.

Tischendorf, L., Bender, D. J. \& Fahrig, L. (2003). Evaluation Of Patch Isolation Metrics In Mosaic Landscapes For Specialist Vs. Generalist Dispersers. Landscape Ecology, 18, 41-50.

Vittor, A. Y., Gilman, R. H., Tielsch, J., Glass, G., Shields, T., Lozano, W. S., Pinedo-Cancino, V. \& Patz, J. A. (2006). The Effect Of Deforestation On The Human-Biting Rate Of Anopheles Darlingi, The Primary Vector Of Falciparum Malaria In The Peruvian Amazon. The American Journal Of Tropical Medicine And Hygiene, 74, 3-11.

Vittor, A. Y., Pan, W., Gilman, R. H., Tielsch, J., Glass, G., Shields, T., Sánchez-Lozano, W., Pinedo, V. V., Salas-Cobos, E. \& Flores, S. (2009). Linking Deforestation To Malaria In The Amazon: Characterization Of The Breeding Habitat Of The Principal Malaria Vector, Anopheles Darlingi. The American Journal Of Tropical Medicine And Hygiene, 81, 5-12.

Wesolowski, A., Qureshi, T., Boni, M. F., Sundsøy, P. R., Johansson, M. A., Rasheed, S. B., Engø-Monsen, K. \& Buckee, C. O. (2015). Impact Of Human Mobility On The Emergence Of Dengue Epidemics In Pakistan. Proceedings Of The National Academy Of Sciences, 112, 11887-11892.

Wongkoon, S., Jaroensutasinee, M. \& Jaroensutasinee, K. (2012). Development Of Temporal Modeling For Prediction Of Dengue Infection In Northeastern Thailand. Asian Pacific Journal Of Tropical Medicine, 5, 249-252.

Ye, Y. \& Fang, X. (2011). Spatial Pattern Of Land Cover Changes 
Across Northeast China Over The Past 300 Years. Journal Of Historical Geography, 37, 408-417.

Yun, N. E. \& Walker, D. H. (2012). Pathogenesis Of Lassa Fever. Viruses, 4, 2031-2048.

Zhang, H., Qi, Z.-F., Ye, X.-Y., Cai, Y.-B., Ma, W.-C. \& Chen, M.N. (2013). Analysis Of Land Use/Land Cover Change, Population Shift, And Their Effects On Spatiotemporal Patterns Of Urban Heat Islands In Metropolitan Shanghai, China. Applied Geography, 44, 121-133. 